\title{
To Vaccinate or Not to Vaccinate
}

Hepatitis B virus infection is a disease that is associated with significant morbidity and mortality. Hepatitis D virus infection, which requires a coinfection with hepatitis B, is associated with an increased morbidity and mortality over that of hepatitis B virus infection alone. It is transmitted during sexual intercourse through contaminated body fluids, saliva, and blood; in utero; and at delivery. Lateral transmission, which is more common than vertical transmission, should be of particular concern. This virus has the capability of resulting in chronic active infection, cirrhosis, liver failure, and ultimately death.

One method of preventing the spread of this serious infection and maintaining wellness is the hepatitis B vaccine. The recombinant form causes no significant adverse reactions in the recipient. It is safe to administer, even in pregnancy.

Perhaps a program of vaccinations should be instituted for all individuals who have yet to be exposed to the hepatitis $B$ virus. A vaccination program would be particularly prudent for adolescents who are sexually active because these young people are likely to have multiple sexual partners, therefore raising their risk. Since the acquisition of this virus may come from a variety of sources, the vaccination of all pregnant patients who have not been exposed to the virus would be warranted, especially considering that vaccination in the pregnant patient would also provide protection for her fetus.

Opinions on this subject would be welcomed from our readers.

Sebastian Faro, M.D., Ph.D.

Editor-in-Chief 


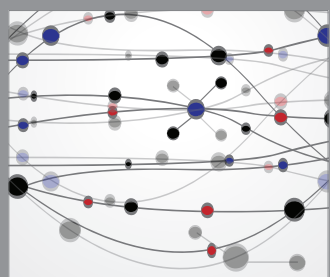

The Scientific World Journal
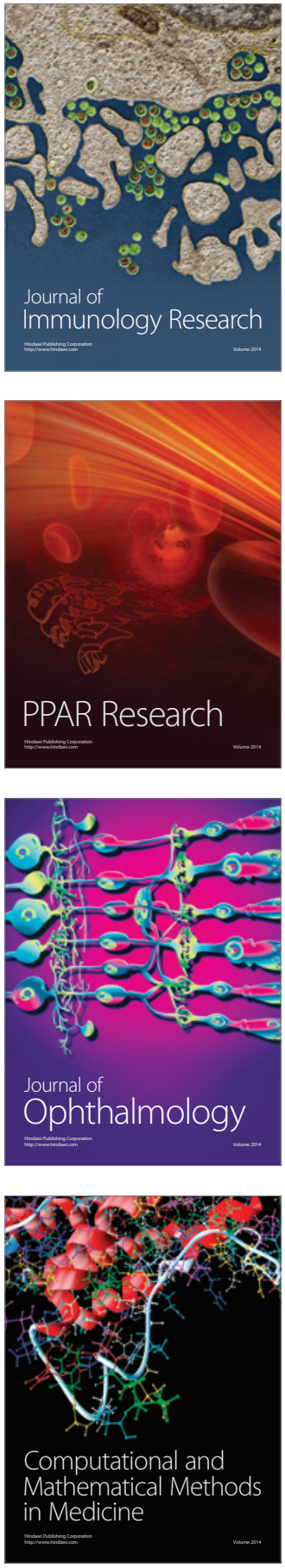

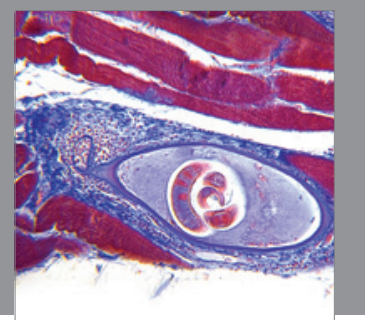

Gastroenterology

Research and Practice
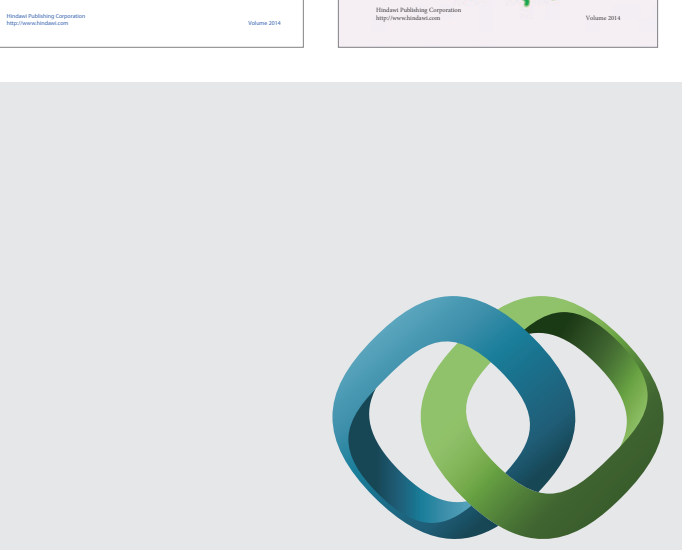

\section{Hindawi}

Submit your manuscripts at

http://www.hindawi.com
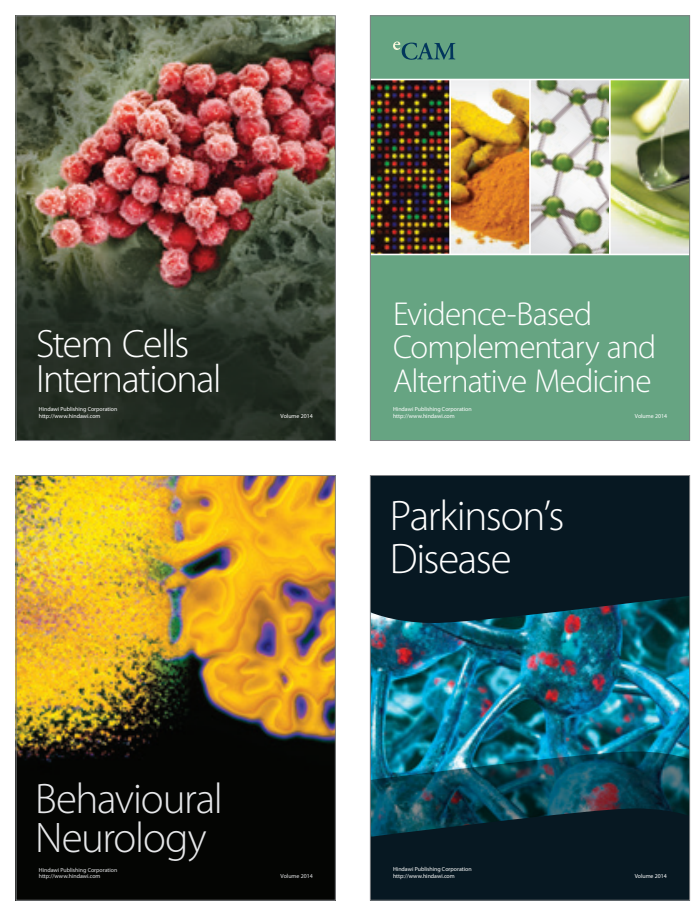

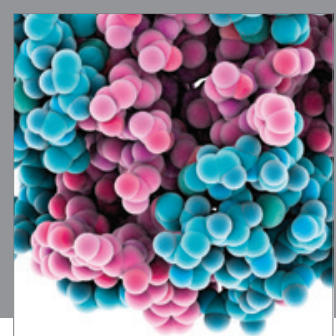

Journal of
Diabetes Research

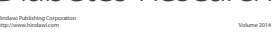

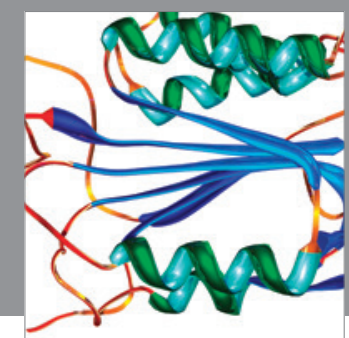

Disease Markers
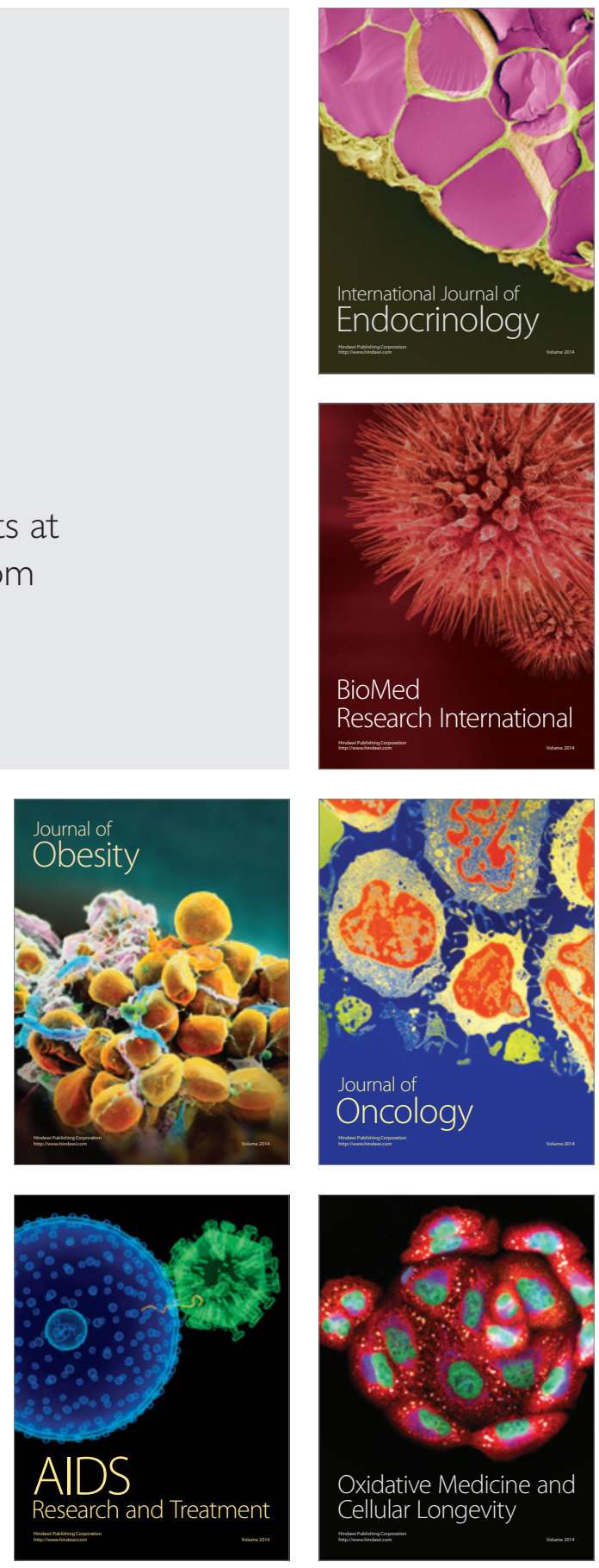